Cumhuriyet International Journal of Education-CIJE

e-ISSN: $2147-1606$

Vol 4 (3), 2015, $10-30$

\title{
Investigating Of Pedagogical Content Knowledge of Pre-Service Primary Teachers' Related To the Length Measurement in the Context Students' Understanding
}

\author{
Nurullah ŞİMŞEK ${ }^{1}$, Nihat BOZ ${ }^{2}$
}

\section{Summary}

\section{PURPOSE AND SIGNIFICANCE}

When the literature relevant to the length measurement is reviewed, it is seen that many misconceptions are reported. It is thought that raising primary school teacher, who are aware of the misconceptions and well informed about the student's learning is of great importance in addressing these different understanding. Because it is of great significance for the doctor to diagnose the disease. Within this scope, the aim of the study is to investigate whether the pre-service primary teacher are able to determine the different understanding of counting the points and the lines on the ruler instead of counting the units, which is a very frequently observed misconception among the students or not.

\section{METHODS}

In this study qualitative method was used at general level and case study was used in at special level as the research model. The study was performed with the participation of 84 preservice primary teachers. Firstly, a questionnaire was applied to 85 pre-service primary teachers that participated into the study. Later, by taking the categories obtained as a result of the questionnaire analysis and voluntariness principle into consideration, interviews with 4 teacher candidates were conducted. Descriptive analysis was performed on the data. The data obtained from the questionnaires and the interviews were analyzed together.

\section{RESULTS}

At the end of the analysis of the data obtained, the answers given by the pre-service teachers were collected within three categories. $59 \%$ of the teacher candidates were placed in the category which included the candidates who were not aware of the different understanding, $20 \%$ of them were placed in the category which included the candidates who were aware of the different understanding but who did not express it in the right way and $21 \%$ of them were placed in the category which included the candidates who were aware of the different understanding and expressed it in the right way.

\section{DISCUSSION AND CONCLUSIONS}

In view of the findings obtained from the interviews performed with the teacher candidates from the first two categories, it is seen that teacher candidates are not able to understand length measurement conceptually. It can be said the 21st, 52nd and 6th teacher candidates are not able to establish the relationship between quality, quantity and the unit. It is thought that teacher candidates cannot identify different understanding as a result of the fact that they have limited field information with regard to length measurement subject. This situation illustrates the relationship between field information and student information, which is sub-component of pedagogical field information. On the other hand, the perception way that students possess with respect to the length measurement subject was also observed in 52nd teacher candidate. It is thought that this situation has an impact on teacher candidate's identifying the misconception that student has.

\footnotetext{
1 Res. Assist., Cumhuriyet University Faculty of Education, nurullah4006@gmail.com

2 Assoc. Prof. Dr., Gazi University Faculty of Education, boz@gazi.edu.tr
} 